\title{
Crystallization of Amorphous Poly(Lactic Acid) Induced by Vapor of Acetone to Form High Crystallinity and Transparency Specimen
}

\author{
Naofumi Naga ${ }^{1}$, Yuji Yoshida ${ }^{1}$, Keiichi Noguchi ${ }^{2}$, Shigemitsu Murase ${ }^{3}$ \\ ${ }^{1}$ Department of Applied Chemistry, Material Science Course, College of Engineering, \\ Shibaura Institute of Technology, Tokyo, Japan \\ ${ }^{2}$ Instrumentation Analysis Center, \\ Tokyo University of Agriculture and Technology, Tokyo, Japan \\ ${ }^{3}$ Department of Organic and Polymer Materials Chemistry, Faculty of Technology, \\ Tokyo University of Agriculture and Technology, Tokyo, Japan \\ Email: nnaga@sic.shibaura-it.ac.jp
}

Received December 24, 2012; revised January 24, 2013; accepted January 30, 2013

Copyright (C) 2013 Naofumi Naga et al. This is an open access article distributed under the Creative Commons Attribution License, which permits unrestricted use, distribution, and reproduction in any medium, provided the original work is properly cited.

\begin{abstract}
Crystallization of amorphous poly(lactic acid) (PLA) was investigated by exposing to vapor of acetone. The vapor of acetone induced crystallization of the amorphous PLA effectively. It took about 24 min to complete the crystallization of a $1 \mathrm{~cm} \times 2 \mathrm{~cm} \times 0.55 \mathrm{~mm}$ specimen at $25^{\circ} \mathrm{C}$. The crystallization rate increased with increasing of conducting temperature. The crystallization method yielded high crystallinity about $40 \%$, which was almost equal to that attained by annealing or immersion methods conducted as references. The specimens crystallized by the vapor showed higher transparency than those prepared by the reference methods. The crystallization was induced by diffusion of acetone into the amorphous phase of PLA, and polarized optical photomicrographs cleared that the diffusion obeyed Fick type diffusion.
\end{abstract}

Keywords: Poly(Lactic Acid); Acetone; Crystallization; Transparency

\section{Introduction}

Poly(lactic acid) (PLA) is one of the most useable bioderadable plastics which are made from bio-resources. PLA is used in various products, for example film, sheet, fiber, resin, and so on [1-3]. Improvement of the mechanical property and processability of PLA will expand the application of PLA. Crystallization rate and crystallinity of PLA are relatively low due to its slow nucleation $[4,5]$, and its slow crystallization causes long molding cycle for producing of products. Addition of a nucleating agent to PLA is effective to improve the crystallization rate, and some nucleating agents, such as benzoic acid hydrazide, for PLA have been developed [6-14]. Nanocomposite of PLA is an effective method to improve the mechanical properties and increased the crystallization rate of PLA [15-19].

We found out crystallization of amorphous PLA induced by immersion it in organic solvents [20]. Acetone is the most effective among the organic solvents used in the experiments. This is a very easy and conventional method to obtain high crystalline PLA samples. However, this method yields whitened PLA specimens due to the forming small bubbling accompanied by immersion of the specimens in acetone. The problem which we must solve next is to fide a method for preparing high crystallinity with high transparency specimen of PLA.

We came to an idea that use of vapor of organic solvent to induce crytslallization of amorphous PLA. For example, crystallization of amorphous syndiotacic-polystyrene induced was induced by vapor of toluene [21]. It may offer the key to attain the crystallization of PLA without whitening. In this paper, we investigated solvent induced crystallization of amorphous PLA and its properties precisely, and found out that vapor of acetone induced crystallization of amorphous PLA effectively and yielded not only high crystallinity but also transparent specimens.

\section{Experimental Part}

\subsection{Materials}

Sheet of amorphous PLA was kindly donated from Uni- 
tika Ltd., and was used as received. Number average molecular weight $\left(M_{\mathrm{n}}\right)$ and molecular weight distribution $\left(M_{\mathrm{w}} / M_{\mathrm{n}}\right)$ of the PLA were 83,600 and 2.5 , respectively, calibrated with standard polystyrene samples. Sample sheet for the crystallization was cut as a size of $1 \mathrm{~cm} \times 2$ $\mathrm{cm} \times 0.55 \mathrm{~mm}$. Sample for polarized optical micrograph was prepared on the slide glass covered with cover glass. The sample was melted at $220^{\circ} \mathrm{C}$ for 5 min and rapidly cooled to room temperature. Acetone was commercially obtained and used without further purification.

\subsection{Crystallization of Amorphous PLA}

The crystallization was conducted in a $100 \mathrm{ml}$ Erlenmeyer flask in the presence of $20 \mathrm{~mL}$ of acetone at desired temperatures. The amorphous PLA sample was exposed to the acetone vapor for desired time, and dried in vacuo at room temperature for $6 \mathrm{~h}$. The sample was placed at room temperature for 1 week before DSC measurement.

Crystallization of amorphous PLA was also conducted by annealing at $90^{\circ} \mathrm{C}$ or immersion in acetone at $25^{\circ} \mathrm{C}$.

\subsection{Analytical Procedures}

Thermal properties of the PLA samples were investigated by a Rigaku DSC 8230 at a heating rate of $3^{\circ} \mathrm{C} / \mathrm{min}$ to $200^{\circ} \mathrm{C}$ after previous cooling to $0^{\circ} \mathrm{C}$ and holding for 5 min. Haze of the specimen was determined by a Nippon Denshoku Industries Co., Ltd. NDH-2000. Polarized optical micrographs of the PLA were observed using an optical microscope (Olympus BX50). Wide angle X-ray diffraction (WAXD) patterns of the PLA samples were recorded on a Rigaku RAD-C using $\mathrm{Cu} \mathrm{K}$ radiation.

\section{Results and Discussion}

\subsection{Structure and Properties of PLA Specimens Crystallized by Acetone Vapor}

Amorphous PLA was exposed to the vapor of acetone at $25^{\circ} \mathrm{C}, 40^{\circ} \mathrm{C}$, and $50^{\circ} \mathrm{C}$. WAXD patterns of the specimens are shown in Figure 1. The specimens exposed to acetone vapor showed clear diffraction peaks at $2=14.7^{\circ}$, $16.5^{\circ}, 18.9^{\circ}$, and $22.3^{\circ}$. These diffraction peaks are derived from $010,110 / 200,203$, and 015 phases of form, respectively [22-24]. These diffraction peaks are not detected in the amorphous sample but detected in a thermally crystallized sample. The results clear that amorphous PLA can be crystallized by acetone vapor and the crystal preferentially forms the form.

Properties of PLA specimens are summarized in Table 1. The properties of the PLA samples, which are amorphous, immersed in acetone, and thermally crystallized samples, are also listed for references. Crystallinity values of all the crystallized samples induced by acetone vapor were more than $40 \%$. The values are as high as that of the crystallized samples by immersion in acetone and annealing at $90^{\circ} \mathrm{C}$. Photographs of the specimens are shown in Figure 2. The specimen crystallized in acetone solvent is whitened as described above. Whereas, the crystallized samples induced by acetone or annealing are highly transparent. Haze values are also summarized in Table 1. The crystallized samples induced by acetone vapor showed low haze values than that of the thermally crystallized sample.

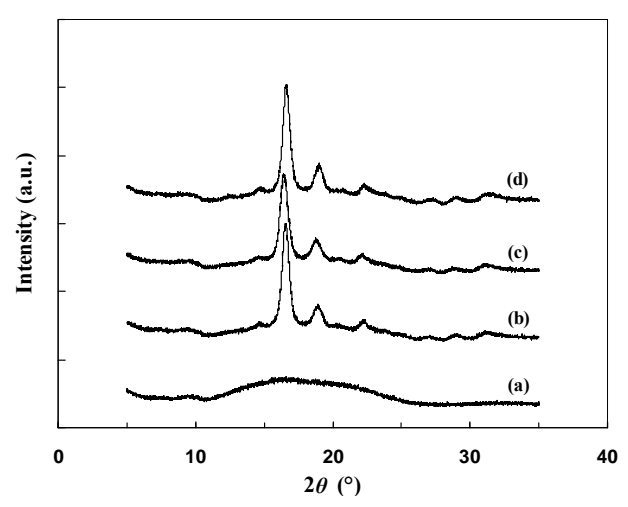

Figure 1. WAXD profiles of PLA samples; amorphous PLA (a), exposed to acetone vapor at $25^{\circ} \mathrm{C}(\mathrm{b}), 40^{\circ} \mathrm{C}(\mathrm{c})$, and $50^{\circ} \mathrm{C}$ (d).

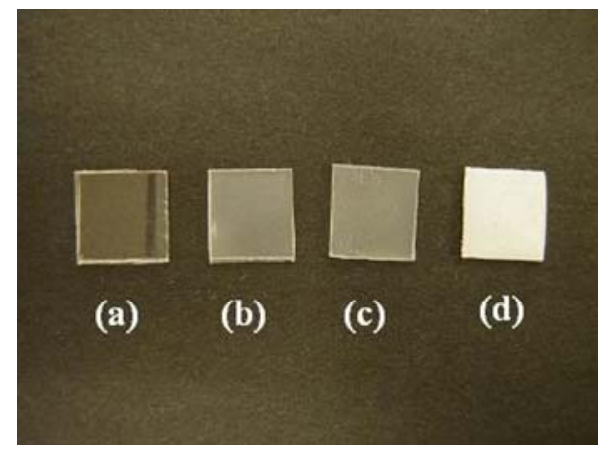

Figure 2. Photographs of PLA samples; amorphous PLA (a), exposed to acetone at $25^{\circ} \mathrm{C} \mathrm{(b),} \mathrm{annealed} \mathrm{at} 90^{\circ} \mathrm{C}$ (c), and immersed in acetone at $25^{\circ} \mathrm{C}(\mathrm{d})$.

Table 1. Properties of PLA samples ${ }^{\mathrm{a}}$.

\begin{tabular}{|c|c|c|c|c|c|c|c|}
\hline Sample & Method & $\begin{array}{c}\text { Temp. } \\
{ }^{\circ} \mathrm{C}\end{array}$ & $\begin{array}{c}\text { Time } \\
\text { min }\end{array}$ & $\begin{array}{c}H_{\mathrm{c}}^{\mathrm{b}} \\
\mathrm{J} / \mathrm{g}\end{array}$ & $\begin{array}{c}H_{\mathrm{m}}{ }^{\mathrm{b}} \\
\mathrm{J} / \mathrm{g}\end{array}$ & $\begin{array}{c}X_{\mathrm{c}}^{\mathrm{c}} \\
\% \\
\end{array}$ & $\begin{array}{c}\text { Haze } \\
\% \\
\end{array}$ \\
\hline $1^{\mathrm{d}}$ & --- & --- & --- & 38.1 & 39.6 & 1.6 & 6.7 \\
\hline 2 & Vapor $^{\mathrm{e}}$ & 25 & 60 & & 38.0 & 40.9 & 65.9 \\
\hline 3 & Vapor $^{\mathrm{e}}$ & 40 & 20 & & 39.7 & 42.7 & 76.1 \\
\hline 4 & Vapor ${ }^{\mathrm{e}}$ & 50 & 20 & & 40.9 & 44.0 & 83.2 \\
\hline 5 & Annealing & 90 & 270 & & 40.5 & 43.5 & 90.5 \\
\hline 6 & Immersion $^{\mathrm{f}}$ & 25 & 10 & & 40.4 & 43.4 & \\
\hline
\end{tabular}

${ }^{\mathrm{a}}$ Sample: $10 \times 20 \times 0.55 \mathrm{~mm},{ }^{\mathrm{b}}$ Heat of fusion of crystallization $\left(H_{\mathrm{c}}\right)$ or melting $\left(H_{\mathrm{m}}\right)$ on the heating process determined by DSC, ${ }^{\mathrm{c}}$ Crystallinity determined by Equation (1), Amorphous sample, ${ }^{\mathrm{e}}$ Exposed to acetone vapor, Immersed in acetone. 


\subsection{Crystallization Behavior of Amorphous PLA by Acetone Vapor}

The crystallization process of amorphous PLA in acetone was also traced with DSC. Figure 3 shows time evolution of DSC thermograms of the PLA exposed to acetone vapor at $25^{\circ} \mathrm{C}$. In the DSC profile of the amorphous PLA (Figure 3. $0 \mathrm{~min}$ ), endothermic and exothermic peaks derived from glass transition, crystallization of amorphous phase, and melting of crystalline phase were detected at $60^{\circ} \mathrm{C}, 110^{\circ} \mathrm{C}$, and $165^{\circ} \mathrm{C}$, respectively [25-27]. Multiple melting peaks at around $161^{\circ} \mathrm{C}$ and $166^{\circ} \mathrm{C}$ in the DSC curve of amorphous PLA sample should be derived from transition from $\alpha$ to phase as previously reported [28]. The samples exposed to acetone vapor for $3-18$ min showed a $T_{\mathrm{g}}\left(T_{\mathrm{gl}}\right)$ ranging from $40^{\circ} \mathrm{C}-30^{\circ} \mathrm{C}$, which was lower than that of the amorphous PLA ( $T_{\mathrm{gh}}$ at around $60^{\circ} \mathrm{C}$ ). Two exothermic peaks of the crystallization were detected in the PLA samples exposed to acetone vapor for 3 - $18 \mathrm{~min}$. Those were low $T_{\mathrm{c}}\left(T_{\mathrm{cl}}\right)$ ranging from $80^{\circ} \mathrm{C}$ to $60^{\circ} \mathrm{C}$ and high $T_{\mathrm{c}}\left(T_{\mathrm{ch}}\right)$ ranging from $110^{\circ} \mathrm{C}$ to $85^{\circ} \mathrm{C}$, and these temperatures decreased with increasing of the conducting time. Only an exothermic peak derived from crystallization was detected at around $60^{\circ} \mathrm{C}$ in the sample exposed for $21 \mathrm{~min}$, and the peak disappeared in the sample immersed for $24 \mathrm{~min}$. Vapor induced crystallization takes longer time for crystallization than that induced by immersion in the solvent, the results of DSC profiles are resemble each other. The DSC profiles can be explained by the supposing three phases in the PLA samples, amorphous phase without acetone (Area 1), amorphous phase containing small amount of acetone (Area 2), and crystalline phase (Area 3), as previously proposed in the PLA samples crystallized in acetone solvent [20]. The contained acetone would play a role of like a plasticizer, and decrease $T_{\mathrm{g}}$ and $T_{\mathrm{c}}$ to $T_{\mathrm{gl}}$ and $T_{\mathrm{cl}}$ in the Area 2. The $T_{\text {ch }}$ also decreased with increasing the conducting time, indicating the crystallization of Area 2 would induce the crystallization of Area 1. The DSC

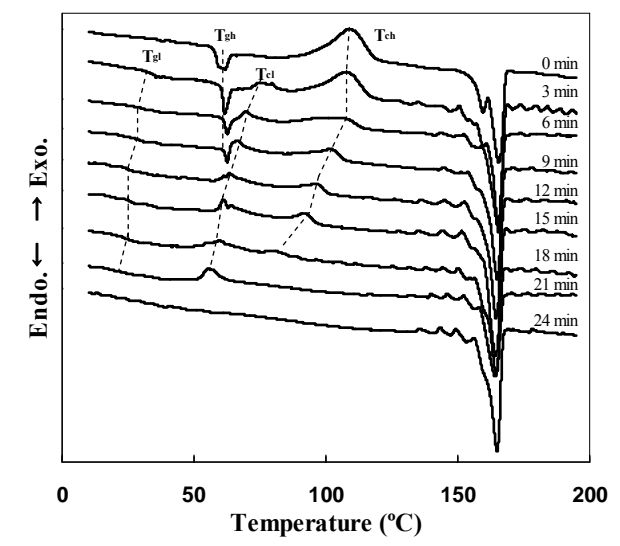

Figure 3. Time evolution of DSC profiles of PLA sample exposed to acetone vapor at $25^{\circ} \mathrm{C}$. profile of the sample exposed for $21 \mathrm{~min}$ did not show $T_{\text {ch }}$ indicating that acetone vapor had reached to the center of the specimen. The DSC profile of the sample exposed to acetone for $24 \mathrm{~min}$ did not show any $T_{\mathrm{c}}$ indicating the crystallization had completed.

The melting enthalpy of total crystalline phase $\left(H_{\mathrm{m}}\right)$ corresponds to the sum of melting enthalpies of original crystalline phase $\left(H_{\mathrm{mc}}\right)$ and crystallized amorphous phase $\left(H_{\mathrm{ma}}\right)$. In the case of amorphous PLA sample, although a small amount of crystalline phase was contained, the values of $H_{\mathrm{c}}(38.1 \mathrm{~J} / \mathrm{g})$ and $H_{\mathrm{m}}(39.6 \mathrm{~J} / \mathrm{g})$ were almost same, as shown in Table 1. Crystallinity of the original PLA samples $\left(X_{\mathrm{c}}\right)$, therefore, was estimated from enthalpies of crystallization of amorphous phase $\left(H_{\mathrm{c}}\right)$ and melting of total crystalline phase $\left(H_{\mathrm{m}}\right)$ using a following equation, as previously reported [20].

$$
X_{c}=\left(H_{\mathrm{mt}}-H_{\mathrm{ca}}\right) / H_{\mathrm{m}}^{0} \times 100
$$

where, $H_{\mathrm{m}}^{0}$ is theoretical melting enthalpy of PLA, 93 $\mathrm{J} / \mathrm{g}$ [29].

The crystallization at $40^{\circ} \mathrm{C}$ and $50^{\circ} \mathrm{C}$ was also trace by DSC. Relationship between conducting time and $X_{\mathrm{c}}$ is shown in Figure 4 to study the effect of temperature of vapor on the crystallization rate. Increase of the conducting temperature is effective to accelerate the crystallization induced by acetone vapor. The crystallization was completed within $8 \mathrm{~min}$ or $5 \mathrm{~min}$ at $40^{\circ} \mathrm{C}$ or $50^{\circ} \mathrm{C}$, respectively.

Crystallization of amorphous PLA induced by acetone vapor was conducted between cover glass and slide glass on the stage of an optical micrograph to trace the diffusion of the vapor in the specimen. Figure 5 shows the polarized optical micrographs of PLA specimen at around the edge exposed to acetone vapor at $25^{\circ} \mathrm{C}$. The sample before exposure to acetone vapor did not show

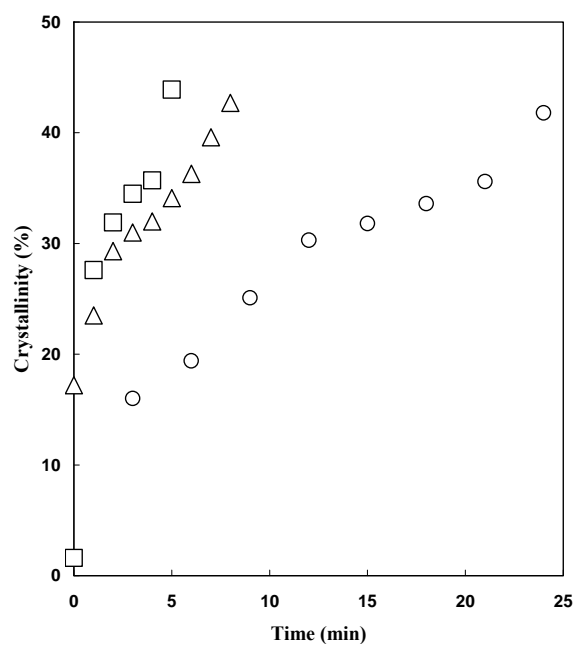

Figure 4. Relationship between exposure time and crystallinity of PLA sample exposed to acetone vapor at $25^{\circ} \mathrm{C}$ (circle), $40^{\circ} \mathrm{C}$ (triangle), and $50^{\circ} \mathrm{C}$ (square). 
birefringence, as shown in Figure 5(a). After the exposure of the sample to acetone vapor, birefringence appeared at where crystalline area. The area which showed the birefringence increased as time passed, as shown in Figures 5(b)-(d). A relationship between conducting time (square root of the time) and crystallization front (length from edge of the specimen to crystallization front) is shown in Figure 6. The plot clears that diffusion distance of acetone is in proportion to square root of the exposed time, indicating the diffusion of acetone vapor in PLA obeys Fick type diffusion [30-32]. These results show good agreement with the results of the PLA crystallization immersed in acetone solvent.

\section{Conclusions}

Crystallization of amorphous PLA was carried out in

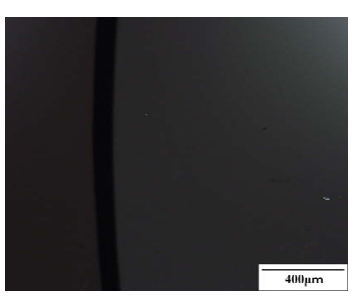

(a)
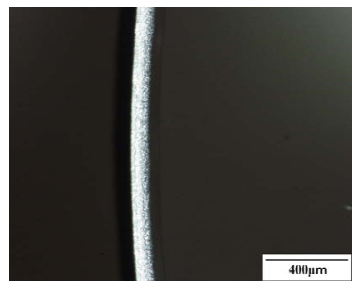

(c)
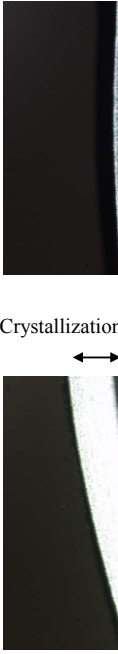

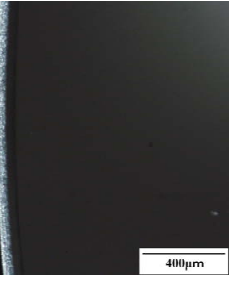

(b)

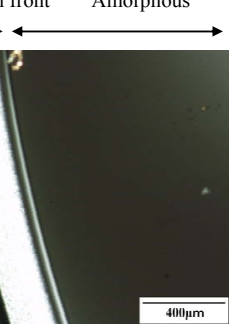

(d)
Figure 5. Polarized optical photomicrographs of PLA exposed to acetone vapor at $25^{\circ} \mathrm{C}$, (a) $0 \mathrm{~min}$, (b) $5 \mathrm{~min}$, (c) 10 min, and (d) $40 \mathrm{~min}$.

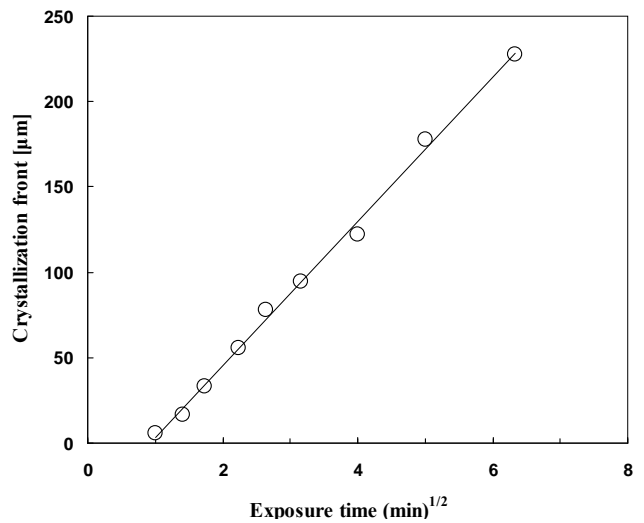

Figure 6. A relationship between exposure time (Square root of time) and crystallization front (length from edged of the specimen to crystallization front) of amorphous PLA sample at $25^{\circ} \mathrm{C}$. acetone vapor. Diffusion of acetone vapor into PLA sample induced the crystallization. This method formed high crystallinity and high transparency PLA specimens. The diffusion of acetone vapor in PLA specimen obeyed Fick type diffusion, and crystallization rate increased with increasing of the conducting temperature.

Solvent vapor induced crystallization should be one of the easy and useful methods to improve the properties of PLA. Although, it took longer time for crystallization than immersion in some organic solvents, it must be useful to make PLA products with high crystallinity and transparency for practical use. For example, it is possible to increase crystallinity of molds or films of PLA without damage of their optical properties. The crystallization can be induced by vapors of various solvents, and selection of chemically safety solvent would make the process practicable.

\section{REFERENCES}

[1] R. Auras, B. Harte and S. Selke, "An Overview of Polylactides as Packaging Materials," Macromolecular Bioscience, Vol. 4, No. 9, 2004, pp. 835-864.

[2] Y. Ikada and H. Tsuji, "Biodegradable Polyesters for Medical and Ecological Applications," Macromolecular Rapid Communication, Vol. 21, No. 3, 2000, pp. 117-132.

[3] J. R. Dorgan, B. Braun, J. R. Wegner and D. M. Knauss, "Degradable Polymers and Materials: Principles and Practice (ACS Symposium Series)," 2006, pp. 102-125.

[4] M. Yasuniwa, S. Tsubakihasra, K. Iura, Y. Ono, Y. Dan and K. Takahashi, "Crystallization Behavior of Poly(L-lactic acid)," Polymer, Vol. 47, No. 21, 2006, pp. 7554-7563. doi:10.1016/j.polymer.2006.08.054

[5] T. Miyata and T. Masuko, "Crystallization Behavior of Poly (L-Lactide),” Polymer, Vol. 39, No. 22, 1998, pp. 5515-5521. doi:10.1016/S0032-3861(97)10203-8

[6] N. Kawamoto, A. Sakai, T. Horikoshi, T. Urushihara and E. Tobita, "Nucleating Agent for Poly(L-Lactic Acid)-An Optimization of Chemical Structure of Hydrazide Compound for Advanced Nucleation Ability," Journal of Appllied Polymer Science, Vol. 103, No. 1, 2007, pp. 198203. doi:10.1002/app.25109

[7] E. Tobita, N. Kawamoto, T. Urushihara, H. Saito, H. Okuyama, T. Kanamori, M. Nakano and H. Okamoto, "Polylactic Acid Resin Compositions, Moldings, and Process for Production Thereof," 2011.

[8] N. Kawamoto, A. Sakai, T. Horikoshi, T. Urushihara and E. Tobita, "Physical and Mechanical Properties of Poly(LLactic Acid) Nucleated by Dibenzoylhydrazide Compound," Journal of Appllied Polymer Science, Vol. 103, No. 1, 2007, pp. 244-250. doi:10.1002/app.25185

[9] M. Yoshimura and Y. Fukuoka, "Lactic Acid Polymer Compositions with Improved Crystallization Rate, Moldability, and Heat and Impact Resistance, Their Manufacture, and Moldings from Them," 2006.

[10] M. Ozawa, Y. Kawamura and M. Kasai, "Polylactic Acid 
Compositions Containing Crystal Nucleating Agents with Accelerated Crystallization and Good Heat Resistance and Moldability," 2005.

[11] N. Sato, T. Noguchi and H. Mori, "Polyester Resin Compositions with Improved Crystallizability," 2004.

[12] H. Nishimura and M. Hioki, "Lactic Acid Polymer Molded Products with Excellent Heat and Impact Resistance and Their Manufacture," 2004.

[13] H. Tsuji, H. Takai and S. K. Saha, "Isothermal and Nonisothermal Crystallization Behavior of Poly(L-Lactic Acid): Effects of Stereocomplex as Nucleating Agent," Polymer, Vol. 47, No. 11, 2006, pp. 3826-3837.

[14] S. Niga, M. Yoshimura and K. Matsumoto, "Lactic Acid Polymer Compositions with Improved Crystallization Rate, Their Moldings with High Crystallinity and Heat Resistance, and Method for Manufacture of the Moldings," 2009.

[15] S. S. Ray, K. Yamada, K. Ueda and M. Okamoto, "Polylactide-Layered Silicate Nanocomposite: A Novel Biodegradable Material," Nano Letters, Vol. 2, No. 10, 2002, pp. 1093-1096. doi:10.1021/n10202152

[16] S. S. Ray, P. Maiti, M. Okamoto, K. Yamada and K. Ueda, "New Polylactide/Layered Silicate Nanocomposites. Preparation, Characterization, and Properties," Macromolecules, Vol. 35, No. 8, 2002, pp. 3104-3110.

[17] P. Maiti, M. Okamoto, K. Yamamda, K. Ueda and K. Okamoto, "New Polylactide/Layered Silicate Nanocomposites: Role of Organoclays," Chemistry of Materials, Vol. 14, No. 11, 2002, pp. 4654-4661. doi: $10.1021 / \mathrm{cm} 020391 \mathrm{~b}$

[18] J. Y. Nam, S. S. Ray and M. Okamoto, "Crystallization Behavior and Morphology of Biodegradable Polylatide/ Layered Silicate Nanocomposite," Macromolecules, Vol. 36, No. 19, 2003, pp. 7126-7131. doi:10.1021/ma034623j

[19] R. Hiroi, S. S. Ray, M. Okamoto and T. Shiroi, "Organically Modified Layered Titanate: A New Nanofiller to Improve the Performance of Biodegradable Polylactide," Macrmolecular Rapid Communications, Vol. 25, No. 15, 2004, pp. 1359-1364. doi:10.1002/marc.200400173

[20] N. Naga, Y. Yoshida, M. Inui, K. Noguchi and S. Murase, "Crystallization of Amorphous Poly(Lactic Acid) Induced by Organic Solvents," Journal of Applied Polymer Science, Vol. 119, No. 4, 2011, pp. 2058-2064. doi:10.1002/app.32890

[21] K. Tashiro and Y. Ueno, "Molecular Mechanism of Solvent-Induced Crystallization of Syndiotactic Polystyrene Glass. 1. Time-Resolved Measurements of Infrred/Raman Spectra and X-Ray Diffraction," Macromolecules, Vol. 34, No. 2, 2001, pp. 310-315. doi:10.1021/ma001659s

[22] P. Pan, B. Zhu and Y. Inoue, "Effect of Crystallization Temperature on Crystal Modifications and Crystallization
Kinetics of Poly(L-Lactide)," Journal of Applied Polymer Science, Vol. 107, No. 1, 2008, pp. 54-62.

doi:10.1002/app.27102

[23] J. Zhang, Y. Duan, H. Sato, H. Tsuji, I. Noda, S. Yan and Y. Ozaki, "Crystal Modifications and Thermal Behavior of Poly(L-Lactic Acid) Revealed by Infrared Spectroscopy," Macromolecules, Vol. 38, No. 19, 2005, pp. 8012 8021. doi:10.1021/ma051232r

[24] P. Pan, B. Zhu, W. Kai, T. Dong and Y. Inoue, "Polymorphic Transition in Disordered Poly(L-Lactide) Crystals Induced by Annealing at Elevated Temperatures," Macromolecules, Vol. 41, No. 12, 2008, pp. 4296-4304.

[25] M. Pyda and B. Wunderlich, "Reversing and Nonreversing Heat Capacity of Poly(Lactic Acid) in the Glass Transition Region by TMDSC," Macromolecules, Vol. 38, No. 25, 2005, pp. 10472-10479. doi:10.1021/ma051611k

[26] J. Zhang, Y. Liang, J. Yan and J. Lou, "Study of the Molecular Weight Dependence of Glass Transition Temperature for Amorphous Poly(L-Lactide) by Molecular Dynamics Simulation," Polymer, Vol. 48, No. 16, 2007, pp. 4900-4905. doi:10.1016/i.polymer.2007.06.030

[27] E. Zuza, J. M. Ugartmendia, A. Lopez, E. Meauiro, A. Leiardi and J. R. Sarasua, "Glass Transition Behavior and Dynamic Fragility in Polylactides Containing Mobile and Rigid Amorphous Fractions," Polymer, Vol. 49, No. 20, 2008, pp. 4427-4432. doi:10.1016/j.polymer.2008.08.012

[28] J. Zhang, K. Tashiro, H. Tsuji and A. J. Domb, "Disorder-to-Order Phase Transition and Multiple Melting Behavior of Poly(L-Lactide) Investigated by Simultaneous Measurements of WAXD and DSC," Macromolecules, Vol. 41, No. 4, 2008, pp. 1352-1357. doi: $10.1021 / \mathrm{ma} 0706071$

[29] E. W. Fischer, H. J. Sterzel and G. Wegner, "Investigation of the Structure of Solution Grown Crystals of Lactide Copolymers by Means of Chemicals Reactions," Kolloid Zeitschrift \& Zeitschrift fuer Polymere, Vol. 251, No. 11, 1973, pp. 980-990. doi:10.1007/BF01498927

[30] H. Ouyang and C. C. Chen, "Acetone Transport in Poly (Ethylene Terephthalate) and Related Phenomena," Journal of Polymer Science Part B: Polymer Physics, Vol. 36, No. 1, 1998, pp. 163-169.

[31] H. Ouyang and S. H. Shore, "The Mass Transport in Poly (Ethylene Terephthalate) and Related Induced-Crystallization," Polymer, Vol. 40, No. 19, 1999, pp. 5401-5406. doi:10.1016/S0032-3861(98)00764-2

[32] H. Ouyang, W. H. Lee, W. Ouyang, S. T. Shinue and T. M. Wu, "Solvent-Induced Crystallization in Poly(Ethylene Terephthalate) during Mass Transport, Mechanism and Boundary Condition," Macromolecules, Vol. 37, No. 20, 2004, pp. 7719-7723. doi:10.1021/ma0400416 